Article

\title{
Improved Predictive Tools for Structural Properties of Metal-Organic Frameworks
}

\author{
Indrani Choudhuri ${ }^{-1}$ and Donald G. Truhlar *(i) \\ Department of Chemistry, Chemical Theory Center, and Minnesota Supercomputing Institute, University of \\ Minnesota, Minneapolis, MN 55455-0431, USA; indranimoni@gmail.com \\ * Correspondence: truhlar@umn.edu
}

Academic Editor: James W. Gauld

Received: 10 March 2020; Accepted: 24 March 2020; Published: 28 March 2020

check for updates

\begin{abstract}
The accurate determination of structural parameters is necessary to understand the electronic and magnetic properties of metal-organic frameworks (MOFs) and is a first step toward accurate calculations of electronic structure and function for separations and catalysis. Theoretical structural determination of metal-organic frameworks is particularly challenging because they involve ionic, covalent, and noncovalent interactions, which must be treated in a balanced fashion. Here, we apply a diverse group of local exchange-correlation functionals (PBE, PBEsol, PBE-D2, PBE-D3, vdW-DF2, SOGGA, MN15-L, revM06-L, SCAN, and revTPSS) to a broad test set of MOFs to seek the most accurate functionals to study various structural aspects of porous solids, in particular to study lattice constants, unit cell volume, two types of pore size characteristics, bond lengths, bond angles, and torsional angles). The recently developed meta functionals revM06-L and SCAN, without adding any molecular mechanics terms, are able to predict more accurate structures than previously recommended functionals, both those without molecular mechanics terms (PBE, PBEsol, vdW-DF2, and revTPSS) and those with them (PBE-D2 and PBE-D3). To provide a broader test, these two functionals are also tested for lattice constants and band gaps of unary, binary, and ternary semiconductors.
\end{abstract}

Keywords: density functional theory; metal-organic frameworks; structural properties; lattice constant; pore sizes; bond lengths; bond angles

\section{Introduction}

Metal-organic frameworks (MOFs) are microporous and mesoporous solids in which inorganometallic nodes (which may be, for example, metal cations or metal oxide clusters) are connected with organic linkers [1-3]. MOFs have applications and potential applications for gas separation and storage [4-6], energy storage [7,8], photocatalysis [9-11], and other catalytic [12-14] processes. Theory and computation are useful tools to predict the accurate structures of MOFs for the precise understanding of their functional behavior.

Kohn-Sham density functional theory (KS-DFT) is the most popular way to calculate structural parameters of solids [15-19]. The accuracy of a KS-DFT calculation of a system depends on the choice of exchange-correlation (XC) functional. Our study builds on previous work by Sholl and co-workers [20], who studied a set of $12 \mathrm{MOF}$ containing various metal atoms. Of six functionals tested, they found that the PBE-D2, PBE-D3, and vdW-DF2 functionals are most promising for the accurate determination of the structural parameters of the MOFs (lattice parameters, unit cell volume, bonded parameters, and pore descriptors). Because improved functionals have become available since the work of Sholl et al., the present work considers the same set of 12 MOFs (listed in Table 1) studied by Sholl et al. [20] and two other MOFs (UiO-66 and MOF-5 or IRMOF-1, which were added to increase the diversity of the test set) with ten functionals-the three that they found to perform best and seven others. We 
study several structural parameters (lattice constants, pore size, bond length, bond angle, torsional angle, and unit cell volume), and we consider four kinds of functionals:

- GA functionals: gradient approximations in which the energy density depends on the local spin-specific electron densities and their gradients. In particular, we consider PBE [21,22], PBEsol [23], and SOGGA [24] in this group.

- Meta functionals in which the energy density also depends on the spin-specific local kinetic energy densities. In particular, we consider MN15-L [25], revM06-L [26], SCAN [27], and revTPSS [28] in this group.

- GA+MM functionals in which a GA is augmented with molecular mechanics terms. In particular, we consider PBE-D2 and PBE-D3 in this group [29,30].

- A functional with nonlocal correlation, vdW-DF2 [31], which has local exchange and nonlocal correlation.

Because nonlocal Hartree-Fock exchange is very expensive in plane wave codes, most calculations on solids are restricted to using only local exchange (sometimes called semilocal exchange) in which the exchange energy density at a point is approximated in terms of functions evaluated at that point, and both the work of Sholl and coworkers and the present work consider only functionals with local exchange. All functionals considered here except vdW-DF also have local correlation, but an efficient algorithm [32] is available for vdW-DF so the cost is not impractically higher than that of the local functionals. In particular, we found that the relative costs for the calculations reported here with the different kinds of functionals are approximately: GA, 1; GA+MM, 1.2, meta, 1.5-2, and vdW-DF2, 3.5).

Table 1. List of metal-organic frameworks (MOFs) studied here along with their reference codes, metal centers, oxidation states, space groups, and experimental references.

\begin{tabular}{|c|c|c|c|c|c|}
\hline MOF $^{a}$ & $\begin{array}{l}\text { Reference } \\
\text { Code }^{b}\end{array}$ & Metal & $\begin{array}{c}\text { Oxidation } \\
\text { State of Metal }\end{array}$ & $\begin{array}{l}\text { Space } \\
\text { Group }\end{array}$ & Reference $^{c}$ \\
\hline $\mathrm{Ag}_{4} \mathrm{C}_{12} \mathrm{Cl}_{4} \mathrm{O}_{8}$ & RORQOE & $\mathrm{Ag}$ & I & P 21/c & [33] \\
\hline $\mathrm{Cd}_{12} \mathrm{H}_{48} \mathrm{C}_{72} \mathrm{~N}_{72} \mathrm{O}_{48}$ & GUPCÜQ01 & $\mathrm{Cd}$ & II & P 1 & [34] \\
\hline $\mathrm{Cd}_{2} \mathrm{H}_{10} \mathrm{C}_{16} \mathrm{~N}_{4} \mathrm{O}_{10}$ & PIJGEV & $\mathrm{Cd}$ & II & P 1 & [35] \\
\hline $\mathrm{Zn}_{1} \mathrm{H}_{4} \mathrm{C}_{4} \mathrm{O}_{4}$ & OFUWIV01 & $\mathrm{Zn}$ & II & $\mathrm{C} 2$ & [36] \\
\hline $\mathrm{Li}_{8} \mathrm{Zn}_{8} \mathrm{H}_{24} \mathrm{C}_{72} \mathrm{O}_{48}$ & WAJJAU & $\mathrm{Li}, \mathrm{Zn}$ & $\mathrm{Li}(\mathrm{I}), \mathrm{Zn}(\mathrm{II})$ & $\mathrm{P} 4(1) 2(1) 2$ & {$[37]$} \\
\hline $\mathrm{Co}_{2} \mathrm{C}_{8} \mathrm{~N}_{12}$ & HAWVOQ01 & Co & II & P 1 & [38] \\
\hline $\mathrm{Cu}_{3} \mathrm{H}_{4} \mathrm{C}_{10} \mathrm{O}_{10}$ & MURCEH & $\mathrm{Cu}$ & II & P 1 & [39] \\
\hline $\mathrm{Cu}_{8} \mathrm{H}_{8} \mathrm{C}_{8} \mathrm{~N}_{12} \mathrm{Cl}_{8}$ & QEJZUB01 & $\mathrm{Cu}$ & I and II & P 1 & {$[40]$} \\
\hline $\mathrm{Dy}_{2} \mathrm{H}_{12} \mathrm{C}_{12} \mathrm{~N}_{2} \mathrm{O}_{16}$ & YORSII & Dy & III & P 1 & [41] \\
\hline $\mathrm{Fe}_{4} \mathrm{H}_{4} \mathrm{C}_{4} \mathrm{O}_{12}$ & HOGWAB & $\mathrm{Fe}$ & II & P 1 & [42] \\
\hline $\mathrm{Fe}_{4} \mathrm{P}_{4} \mathrm{H}_{16} \mathrm{C}_{8} \mathrm{O}_{24}$ & DEMLIR & $\mathrm{Fe}$ & III & P 1 & [43] \\
\hline $\mathrm{Sm}_{2} \mathrm{H}_{12} \mathrm{C}_{10} \mathrm{O}_{14}$ & KOMJEC & $\mathrm{Sm}$ & III & P 1 & {$[44]$} \\
\hline $\mathrm{Zr}_{24} \mathrm{O}_{128} \mathrm{C}_{192}(\mathrm{UiO}-66)$ & RUBTAK & $\mathrm{Zr}$ & IV & P 1 & {$[45]$} \\
\hline $\mathrm{Zn}_{32} \mathrm{O}_{104} \mathrm{C}_{192} \mathrm{H}_{96}$ (MOF-5) & SAHYIK & $\mathrm{Zn}$ & II & P 1 & [46] \\
\hline
\end{tabular}

${ }^{a}$ Chemical formula of the unit cell of the MOF; ${ }^{b}$ The reference code associated with each structure in the Cambridge Structural Database (CSD) and CoRE MOF database [47]; ${ }^{c}$ Experimental reference.

Table 1 includes the reference code from the Cambridge Structural Database (CSD) and CoRE MOF database [47] of the crystal structure associated with each MOF in the test set. There are nine different metal centers among the twelve MOFs; this includes two lanthanides (Dy and Sm). We considered two different oxidation states of $\mathrm{Cu}\left(\mathrm{Cu}^{+1}\right.$ and $\left.\mathrm{Cu}^{+2}\right)$ and $\mathrm{Fe}\left(\mathrm{Fe}^{+2}\right.$ and $\left.\mathrm{Fe}^{+3}\right)(\mathrm{Table} 1)$, and both magnetic and non-magnetic MOFs are considered in the study.

We also note the work of Tran et al. [48,49], who studied lattice constants, cohesive energies, and bulk moduli of strongly and weakly bound solids and found the best behavior for rev-VDW-DF2 and various meta functionals. The reader is directed to their studies for information complementary to the present study. 


\section{Computational Methods}

We performed all the density functional theory calculations with the latest version (5.4.4) of the Vienna Ab initio Simulation Package (VASP) [50,51] with periodic boundary conditions. The core-valence electron interactions were described by using the projector augmented wave (PAW) method [52]. The kinetic energy cutoff was $520 \mathrm{eV}$ for all calculations (the same as used by Sholl and coworkers [20]). All the lattice constants, cell shapes, and atomic coordinates were fully relaxed during the optimizations. The $\mathrm{C}_{6}$ and $\mathrm{R}_{0}$ parameters for PBE-D2 method for elements $\mathrm{H}-\mathrm{Xe}$ are

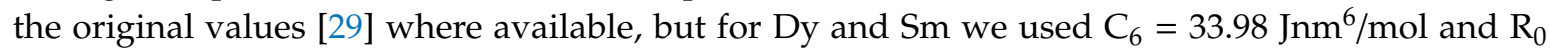
$=2.226 \AA$, as used by Sholl and co-workers [20]. We set a convergence criterion of $10^{-5} \mathrm{eV} \mathrm{for}$ electronic energy minimization and a convergence criterion of $0.0002 \mathrm{eV} / \AA$ on the force on each atom. Monkhorst-Pack $k$-point grids [53] were used as specified in Table S1 (tables with a prefix S are in the Supplementary Materials).

The $\mathrm{Cu}_{3} \mathrm{H}_{4} \mathrm{C}_{10} \mathrm{O}_{10}(\mathrm{MURCEH}) \mathrm{MOF}$ requires additional considerations. We used a $2 \times 1 \times 1$ supercell because the unit cell contains an odd number of metal centers ( $3 \mathrm{Cu}$ centers); the supercell is used to make an even number of metal centers ( $6 \mathrm{Cu}$ centers) in order to study the magnetic ground state. All the structural parameters of MURCEH are calculated based on the $2 \times 1 \times 1$ supercell.

We performed spin-polarized KS-DFT calculations to determine the magnetic ground states. The initial guesses of the number of unpaired electrons on metal centers and the magnetic ground states are listed in Table S1. The magnetic properties of the MOFs are determined based on the number of unpaired electrons in the metal center of the ground state and are listed in Table S1. We used the PBEsol and PBE-D3 functionals to verify the magnetic ground states, and the magnetic ground states of the MOFs determined in our calculations agree well with the experimental results, as well as with the work of Sholl and co-workers [20].

Using the Zeo++ software [54-56], we calculated two kinds of pore sizes, in particular the pore limiting diameter (PLD) and the largest cavity diameter (LCD). The PLD is defined as the diameter of the largest sphere that can move through the MOF. The LCD is defined as the diameter of the largest sphere that can fit in the pore of the MOFs. According to the Zeo++ software website [57], the LCD and PLD are designated as "Di" and "Dif".

To assess the performance of the functionals on the various properties, we calculated the mean signed error (MSE), mean unsigned error (MUE), and mean unsigned percentage error (MUPE) for each combination of functional and property. The errors of the structural parameters (lattice parameters, lattice angles, bond lengths, bond angles, and torsional angles) are defined as the deviations between experimental results and the results calculated by DFT.

We also studied unary, binary, and ternary semiconductors with two of the functionals (revM06-L and SCAN). For these calculations, we used a kinetic energy cutoff of $520 \mathrm{eV}$, a $12 \times 12 \times 12$ Monkhorst-Pack $k$-point mesh, and the same convergence criteria and force criteria as for the MOFs.

\section{Results and Discussion}

\subsection{Lattice Constants and Unit Cell Volume}

The first and most important structural parameters of a solid are the lattice constants. The three lattice constants are designated as $a, b$, and $c$ (see Figure 1). 


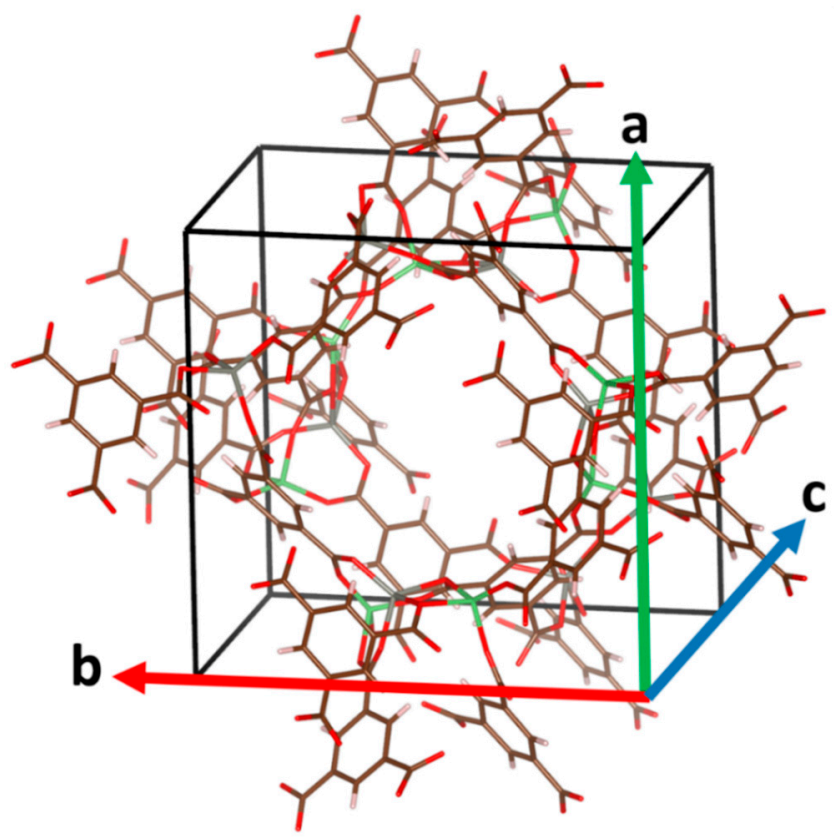

Figure 1. Experimental structure of $\mathrm{Li}_{8} \mathrm{Zn}_{8} \mathrm{H}_{24} \mathrm{C}_{72} \mathrm{O}_{48} \mathrm{MOF}$ (reference code: WAJJAU). The unit cell is bounded by black lines. The directions in which the lattice constants $a, b$, and $c$ are measured are shown as green, red, and blue arrows, respectively.

To ensure that all the crystals are of high quality, the experimental lattice constants of the 14 MOFs are from solvent-free and disorder-free single-crystal X-ray diffraction (XRD) data at room temperature (290-310 K) with an $R$-factor (the measure of the agreement between the experimental X-ray diffraction data and the crystallographic model, also known as residual factor, reliability factor, $R$-value, or $R_{\text {Work }}$ ) of less than 10 [58].

Figure 2a shows the error statistics of the various functionals for predicting lattice constants. The MSEs show that on average, PBE, PBE-D3, vdW-DF2, and revTPSS overestimate the lattice constants, and PBEsol, PBE-D2, SOGGA, MN15-L, revM06-L, and SCAN underestimate them. The SCAN (0.06 ̊) and revM06-L (0.07 $\AA$ ) functionals are the most accurate (i.e., have the smallest MUE). The PBE functional has the largest MUE, which is consistent with what is usually found for PBE for other kinds of solids.

Full details given in the Supplementary Materials show that the maximum deviation of the PBE functional is for $\mathrm{Ag}_{4} \mathrm{C}_{12} \mathrm{Cl}_{4} \mathrm{O}_{8}$ MOF (RORQOE) ( $a=0.50 \AA, b=0.28$ and $c=0.98 \AA$ ), which also agrees well with the results of Sholl and co-workers [20]. However, SCAN and revM06-L have errors in the lattice constants of this MOF that are 5-24 times smaller. SCAN and revM06-L are very accurate for the lattice constants of $\mathrm{Cd}_{12} \mathrm{H}_{48} \mathrm{C}_{72} \mathrm{~N}_{72} \mathrm{O}_{48} \mathrm{MOF}$ (GUPCUQ01); the deviation is only $0.01 \AA$ for both functionals (Table S2). We find that SOGGA and PBEsol are almost equally good for predicting the lattice constants of the MOFs, with MUEs of $0.11 \AA$ for PBEsol and $0.12 \AA$ for SOGGA, although PBEsol has an empirical parameter adjusted to lattice constants, and SOGGA does not. The revM06-L and SCAN functionals are even better and have the lowest MUEs of the functionals studied here.

We also studied the changes in lattice angles of the unit cells of the test sets of MOFs. We found that there is no effect of the functionals on the lattice angles for seven of the MOFs, but there are some changes in lattice angles for the rest of the MOFs. Based on those changes we have calculated the MSE, MUE, and MUPE (given in Table S8) statistics, and these values show that SCAN and revM06-L perform best for this property; both have an MUPE of only $0.3 \%$. 


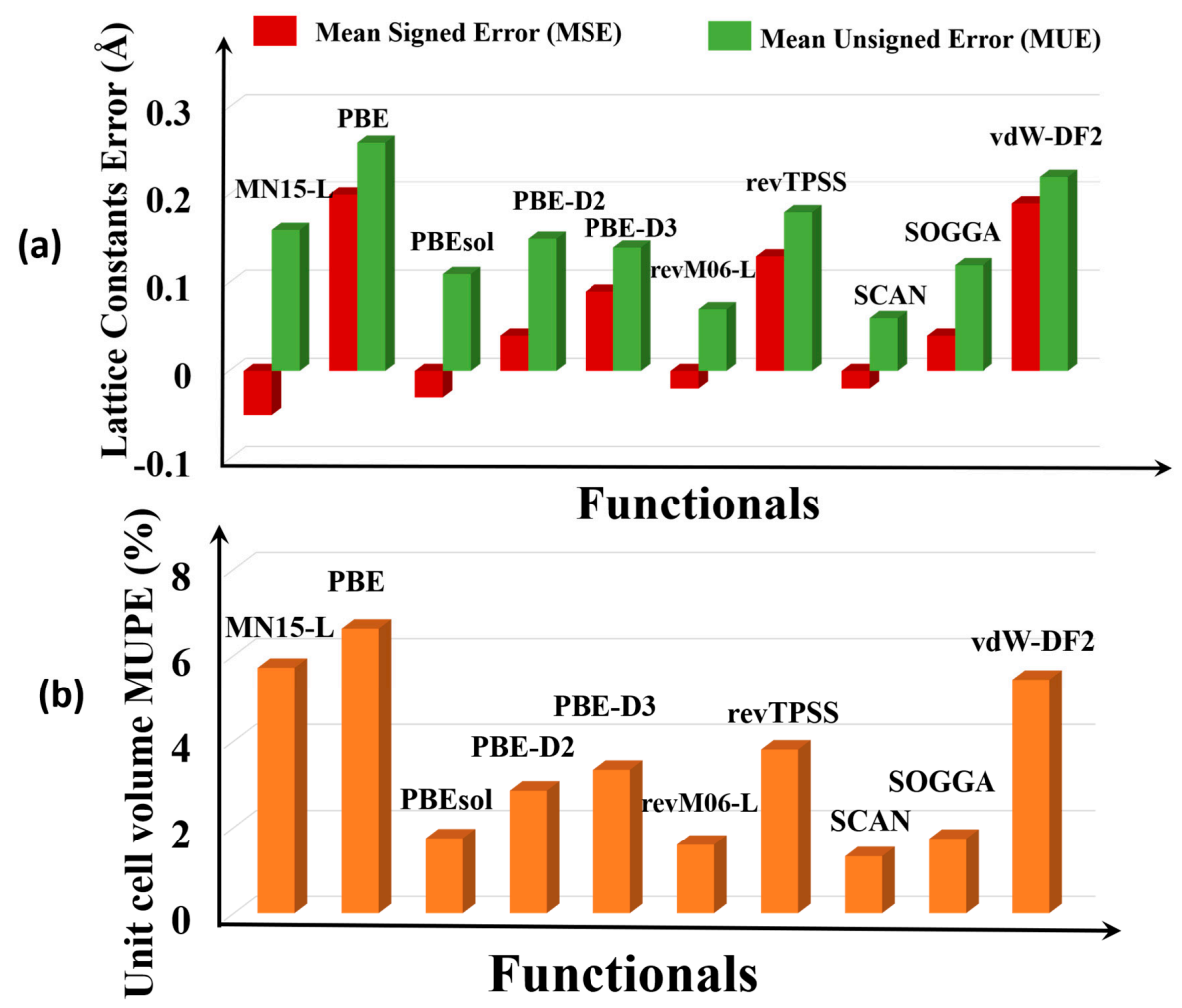

Figure 2. Errors in (a) lattice constants and (b) unit cell volumes.

Unit cell volume is another measure of structure. Figure $2 \mathrm{~b}$ shows that SCAN $(1.3 \%)$ and revM06-L $(\mathrm{MUPE}=1.6 \%)$ are the most accurate functionals for unit cell volume, whereas PBEsol $(1.7 \%)$ and SOGGA (1.7\%) have slightly larger MUPEs, and PBE (6.6 \%), MN15-L (5.7 \%), PBE-D3 (3.3\%), and vdw-DF2 (5.4\%) greatly overestimate unit cell volume. Full details from which these error statistics were calculated are in Table S3.

\subsection{Pore Size}

The accurate prediction of pore diameters is critical for understanding separations and catalytic selectivity. Here, we have studied two different kinds of pore diameters of the MOFs; the LCD and PLD nomenclature (explained in Section 2) is taken from the work of Haldoupis and coworkers [59].

We found that PBE, PBEsol, SOGGA, and revTPSS overestimate both measures of pore size (Figure 3), and PBE-D2, PBE-D3, MN15-L, revM06-L, and SCAN underestimate the LCD and PLD pore sizes of the MOFs. The MUEs show that the most accurate functional for pore sizes is revM06- $\mathrm{L}$, with an MUE of $0.06 \AA$ for PLD and LCD. The SCAN functional is the second best with MUEs of $0.07-0.08 \AA$. PBE and vdW-DF2 and MN15-L have the highest errors, with MUEs in the range 0.13-0.15 $\AA$, about twice as large as for revM06-L and SCAN. 


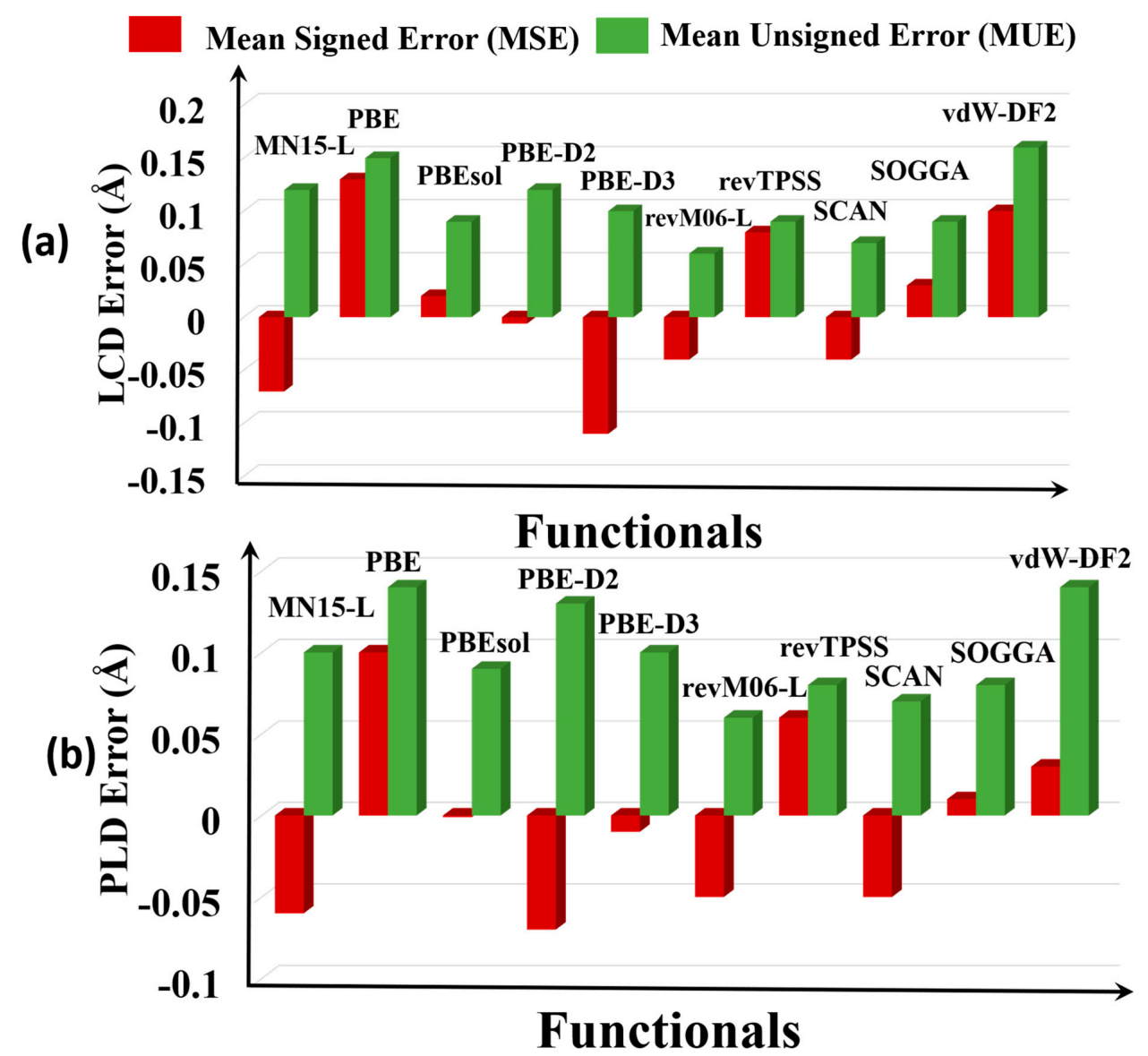

Figure 3. Graphical representation of the errors of pore sizes: (a) largest cavity diameters (LCDs) and (b) pore limiting diameters (PLDs).

\subsection{Bond Lengths}

Bond length is the distance between two bonded atoms. We only considered the bond lengths of the inorganic nodes. We considered 60 bond lengths (Table S5) in the 14 MOFs; among the 60 bond lengths, 2 are metal-chlorine bonds $(\mathrm{M}-\mathrm{Cl}), 6$ are metal-nitrogen bonds $(\mathrm{M}-\mathrm{N})$, and the other 52 bonds are metal-oxygen bonds (M-O). The kinds of bonds included in the tests are $\mathrm{Li}-\mathrm{O}, \mathrm{Fe}-\mathrm{O}, \mathrm{Cu}-\mathrm{O}, \mathrm{Zn}-\mathrm{O}$, $\mathrm{Zr}-\mathrm{O}, \mathrm{Ag}-\mathrm{O}, \mathrm{Cd}-\mathrm{O}, \mathrm{Sm}-\mathrm{O}, \mathrm{Dy}-\mathrm{O}, \mathrm{Co}-\mathrm{N}, \mathrm{Cd}-\mathrm{N}, \mathrm{Cu}-\mathrm{Cl}$, and Ag-Cl.

The PBE and vdW-DF2 functionals highly overestimate the bond lengths (Figure 4); we found that some of the $\mathrm{Ag}-\mathrm{O}, \mathrm{Cd}-\mathrm{O}$, and $\mathrm{Fe}-\mathrm{O}$ bond lengths are overestimated by $0.10 \AA$ by PBE (Table S5). The overestimated bond lengths by PBE and vdW-DF2 are consistent with their overestimation of the lattice constants (Table S2). The $\mathrm{Cu}-\mathrm{N}$ bond in $\mathrm{Cu}_{8} \mathrm{H}_{8} \mathrm{C}_{8} \mathrm{~N}_{12} \mathrm{C}_{18}$ (QEJZUB01) is highly overestimated by $0.23 \AA$ by PBE, as also found by Sholl et al. [20]. The Fe-O bond in $\mathrm{Fe}_{4} \mathrm{H}_{4} \mathrm{C}_{4} \mathrm{O}_{12}$ (DEMLIR) also has large errors for some functionals: 0.23 and $0.18 \AA$ by MN15-L and SOGGA respectively, and this large deviation of the $\mathrm{Fe}-\mathrm{O}$ bond lengths is consistent with the high lattice constant errors for this system (Table S2). Overall, revM06-L has the smallest MUE $(0.026 \AA)$ and SCAN has the second smallest error $(0.027 \AA)$. 


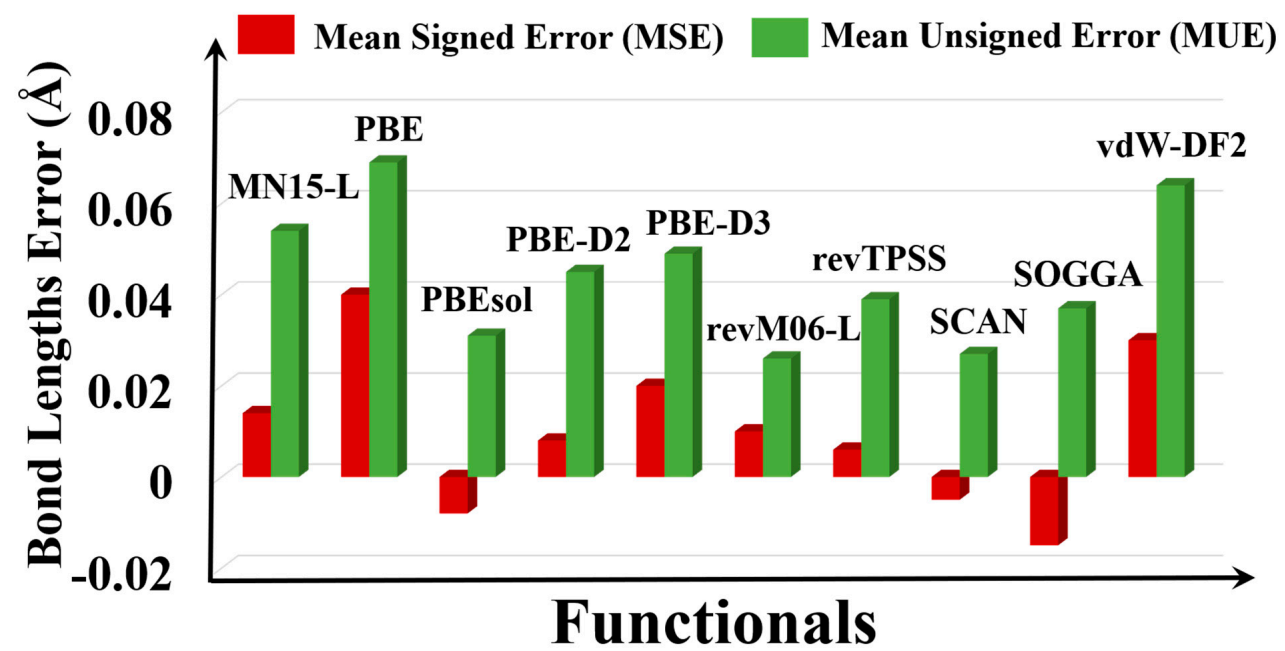

Figure 4. Graphical representation of the errors of bond lengths of the MOFs with respect to different functionals.

\subsection{Bond Angles and Torsional Angles}

A bond angle is the angle between two geminal bonds. We consider 80 bond angles, all in the nodes-in particular $60 \mathrm{O}-\mathrm{M}-\mathrm{O}$ angles, $8 \mathrm{~N}-\mathrm{M}-\mathrm{N}$ angles, $4 \mathrm{O}-\mathrm{M}-\mathrm{Cl}$ angles, $4 \mathrm{M}-\mathrm{O}-\mathrm{M}$ angles, and 2 each of $\mathrm{N}-\mathrm{M}-\mathrm{Cl}$ and $\mathrm{O}-\mathrm{M}-\mathrm{N}$ angles. The kinds of bond angles included in the tests are O-Ag-O, $\mathrm{O}-\mathrm{Cd}-\mathrm{O}, \mathrm{O}-\mathrm{Cu}-\mathrm{O}, \mathrm{O}-\mathrm{Fe}-\mathrm{O}, \mathrm{O}-\mathrm{Zn}-\mathrm{O}, \mathrm{O}-\mathrm{Zr}-\mathrm{O}, \mathrm{O}-\mathrm{Dy}-\mathrm{O}, \mathrm{O}-\mathrm{Sm}-\mathrm{O}, \mathrm{O}-\mathrm{Li}-\mathrm{O}, \mathrm{O}-\mathrm{Cd}-\mathrm{N}, \mathrm{N}-\mathrm{Co}-\mathrm{N}, \mathrm{N}-\mathrm{Cd}-\mathrm{N}$, $\mathrm{O}-\mathrm{Ag}-\mathrm{Cl}, \mathrm{N}-\mathrm{Cu}-\mathrm{Cl}, \mathrm{Li}-\mathrm{O}-\mathrm{Zn}, \mathrm{Zn}-\mathrm{O}-\mathrm{Zn}$, and $\mathrm{Zr}-\mathrm{O}-\mathrm{Zr}$. The error statistics are in Figure $5 \mathrm{a}$.

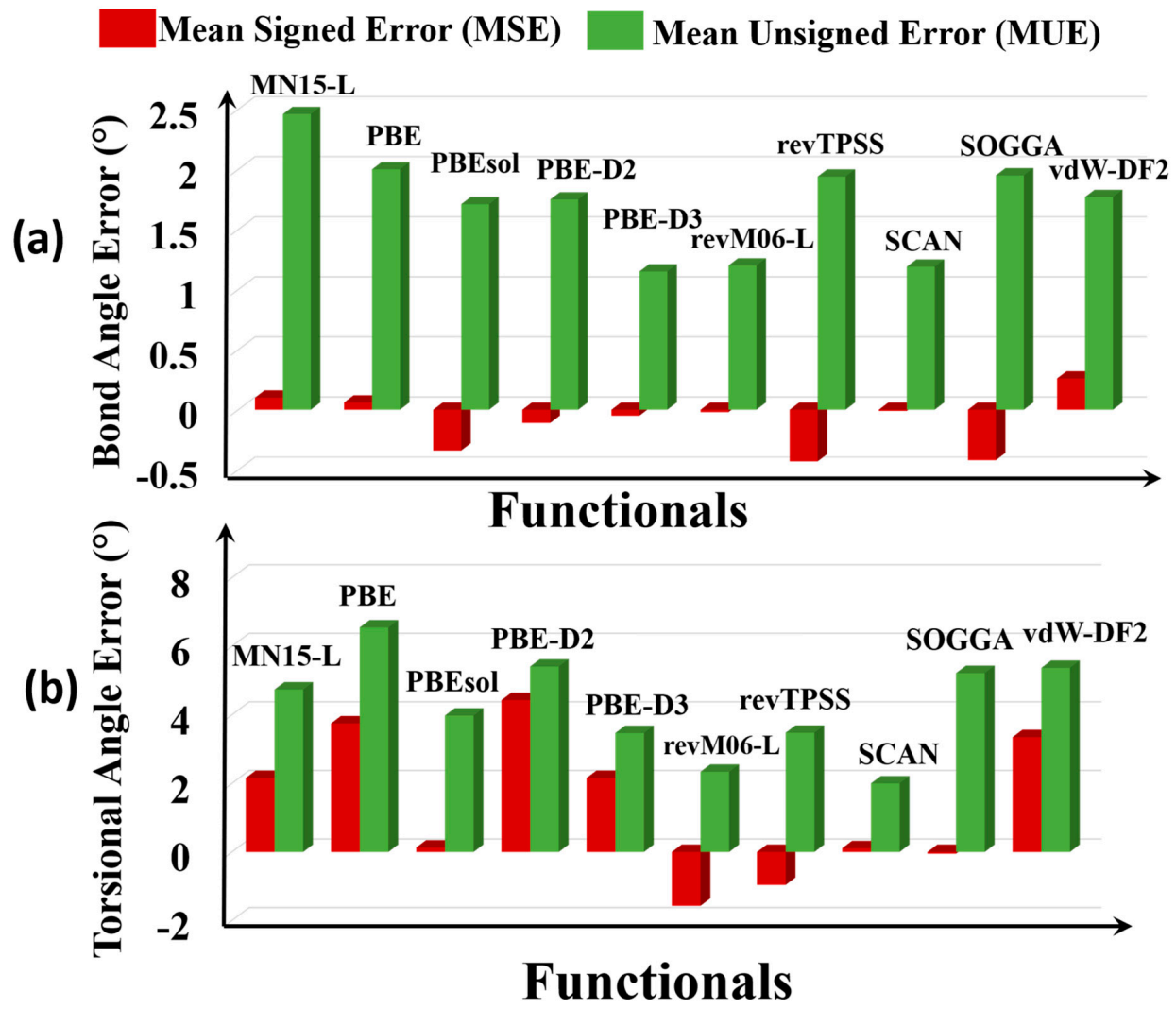

Figure 5. Errors of (a) bond angles and (b) torsional angles. 
The Ag-O-Cl bond angle of $\mathrm{Ag}_{4} \mathrm{C}_{12} \mathrm{Cl}_{4} \mathrm{O}_{8}$ MOF (RORQOE) and the O-Sm-O bond angle in $\mathrm{Sm}_{2} \mathrm{H}_{12} \mathrm{C}_{10} \mathrm{O}_{14} \mathrm{MOF}$ (KOMJEC) are subject to particularly large errors. Overall, MN15-L $\left(2.7^{\circ}\right)$ has the largest MUE among all the functionals studied, and SCAN $\left(1.3^{\circ}\right)$ and revM06-L $\left(1.3^{\circ}\right)$ are the most accurate for this property.

A torsional angle is the angle between the $\mathrm{ABC}$ plane and the $\mathrm{BCD}$ plane in an $\mathrm{A}-\mathrm{B}-\mathrm{C}-\mathrm{D}$ bond sequence. We studied 14 torsional angles on the nodes. The torsions included in the tests are Ag-O-Ag-Cl, Cu-O-Cu-O, Li-O-Zn-O, Cu-Cl-Cu-Cl, Fe-O-P-O, O-Sm-O-C, O-Dy-O-C, O-Fe-O-C, $\mathrm{O}-\mathrm{Zn}-\mathrm{O}-\mathrm{C}, \mathrm{N}-\mathrm{Cd}-\mathrm{N}-\mathrm{C}, \mathrm{O}-\mathrm{Cd}-\mathrm{N}-\mathrm{C}, \mathrm{N}-\mathrm{Co}-\mathrm{N}-\mathrm{C}, \mathrm{Zn}-\mathrm{O}-\mathrm{Zn}-\mathrm{O}$, and $\mathrm{Zr}-\mathrm{O}-\mathrm{Zr}-\mathrm{O}$. The error statistics are in Table S7.

On average, PBE, PBE-D2, PBE-D3, vdW-DF2, MN15-L, SCAN, PBEsol, and SOGGA overestimate the torsional angles (Figure 5b), and revM06-L and revTPSS underestimate them. PBE has the highest MUE (6.6 $)$ among all the functionals; this large MUE is dominated by large errors for $\mathrm{Co}_{2} \mathrm{C}_{8} \mathrm{~N}_{12}$ (HAWVOQ01), $\mathrm{Ag}_{4} \mathrm{C}_{12} \mathrm{C}_{14} \mathrm{O}_{8}$ (RORQOE), $\mathrm{Sm}_{2} \mathrm{H}_{2} \mathrm{C}_{10} \mathrm{O}_{14}$ (KOMJEC), and $\mathrm{Cu}_{3} \mathrm{H}_{4} \mathrm{C}_{10} \mathrm{O}_{10}$ (MURCEH). Among all the functionals, SCAN (MUE $=2.0^{\circ}$ ) most accurately predicts the torsional angles of the MOFs, and revM06-L is the second best $\left(\mathrm{MUE}=2 \cdot 3^{\circ}\right)$.

\subsection{Broader Test on Semiconductors}

The results presented above show that the revM06-L and SCAN functionals give the most accurate results for the structural parameters of MOFs. Since the performance of these two functionals for structural properties of MOFs is similar, we carried out a broader test of these functionals for important crystalline properties, in particular for lattice parameters and band gaps of ten semiconductors, namely $\mathrm{Si}, \mathrm{Ge}, \mathrm{SiC}, \beta-\mathrm{GaN}, \mathrm{CdS}, \mathrm{CdSe}, \mathrm{ZnS}, \mathrm{ZnO}, \mathrm{TiO}_{2}$-anatase, and $\mathrm{TiO}_{2}$-rutile. The results are in Figure 6 and Table S8. This comparison shows that revM06-L and SCAN both are accurate to better than $0.7 \%$ for predicting the lattice constants of the semiconductors, but revM06-L is much more accurate for predicting the band gaps of the semiconductors.

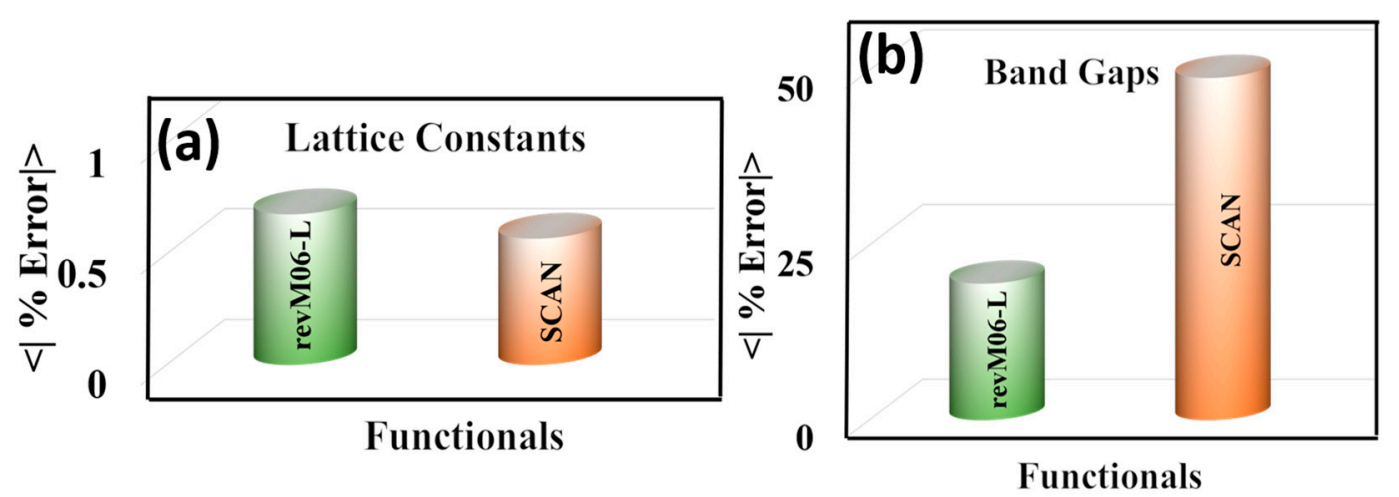

Figure 6. Mean unsigned percentage errors (MUPE) of (a) lattice constants and (b) band gaps of semiconductors.

Previous work in the literature has shown that the band gaps of semiconductors are most accurately determined by hybrid functionals (e.g., HSE06 [60]) and by high-local-exchange functionals (e.g., HLE17 [61,62]). For large systems like MOFs, HLE17 is as accurate as HSE06 with almost 100 times less computational cost [61,62], and for this reason we focus here on local functionals. The previous study showed that HLE17 is far more accurate for predicting the band gaps of unary and binary semiconductors ( $\mathrm{Si}, \mathrm{Ge}, \mathrm{SiC}, \beta-\mathrm{GaN}, \mathrm{CdS}, \mathrm{CdSe}, \mathrm{ZnS}$, and $\mathrm{ZnO}$ ) than local functionals like $\mathrm{PBE}, \mathrm{PBE}+\mathrm{U}$ with $U$ set to $4.0 \mathrm{eV}$, PBEsol, B3LYP, TPSS, GAM, and HCTH/407, but the lattice constants are not accurate [61]. A similar trend was found in our recent paper where HLE17 gave more accurate band gaps for $\mathrm{TiO}_{2}$ (both anatase and rutile) than other local functionals like PBE, PBEsol, and PBE+U $(\mathrm{U}=4.0 \mathrm{eV})$ [62], but HLE17 did not produce good structural parameters. In contrast, the present study shows that the revM06-L and SCAN local functionals are both able to produce good structural 
parameters. There is, however, still a trade-off in that neither of these functionals produces band gaps as accurate as those calculated by HLE17. The key finding of the present section, though, is that the trade-off is less severe with revM06-L than with SCAN, because revM06-L yields more accurate band gaps than SCAN.

\section{Conclusions for MOFs}

We studied the structural parameters-lattice parameters, unit cell volume, bond lengths, bond angles, torsional angles, and pore sizes (largest cavity diameters and pore limiting diameters) of a diverse set of $14 \mathrm{MOF}$ with nine local functionals and one nonlocal functional. The mean unsigned percentage errors (MUPEs) for the various properties are summarized in Table 2. The last column of the table averages these MUPEs to get an average MUPE (AMUPE) to provide a more global summary of the present findings. The three functionals previously [20] found to be most accurate have AMUPEs of 3.0-3.5\%. Five of the functionals introduced in the present study have smaller AMUPEs than that, namely SCAN (1.5\%), revM06-L (1.7\%), PBEsol (2.4\%), SOGGA (2.5\%), and revTPSS (2.5\%). Thus, these functionals, especially SCAN and revM06-L, are highly recommended for future work on the computational design of MOFs.

Table 2. Mean unsigned percentage errors (MUPE) and average mean unsigned percentage error (AMUPE) of structural parameters of MOFs.

\begin{tabular}{|c|c|c|c|c|c|c|c|c|c|}
\hline & $\begin{array}{c}\text { Lattice } \\
\text { Constant }\end{array}$ & $\mathrm{LCD}^{a}$ & $\operatorname{PLD}^{b}$ & $\begin{array}{l}\text { Bond } \\
\text { Length }\end{array}$ & $\begin{array}{c}\text { Bong } \\
\text { Angle }\end{array}$ & $\begin{array}{l}\text { Torsional } \\
\text { Angle }\end{array}$ & $\begin{array}{c}\text { Unit } \\
\text { Cell } \\
\text { Volume }\end{array}$ & $\begin{array}{l}\text { Lattice } \\
\text { Angle }\end{array}$ & $\mathrm{AMUPE}^{c}$ \\
\hline PBE & 2.81 & 6.43 & 7.29 & 3.05 & 2.18 & 4.85 & 6.62 & 1.35 & 4.32 \\
\hline PBEsol & 1.26 & 3.43 & 4.65 & 1.38 & 1.81 & 2.98 & 1.74 & 2.25 & 2.43 \\
\hline revM06-L & 0.78 & 3.00 & 3.47 & 1.16 & 1.31 & 1.67 & 1.59 & 0.32 & 1.66 \\
\hline revTPSS & 1.83 & 3.62 & 4.19 & 1.79 & 1.93 & 2.47 & 3.86 & 0.40 & 2.51 \\
\hline SCAN & 0.72 & 2.65 & 3.34 & 1.22 & 1.26 & 1.42 & 1.32 & 0.29 & 1.52 \\
\hline SOGGA & 1.42 & 3.62 & 4.23 & 1.68 & 2.13 & 3.57 & 1.73 & 1.36 & 2.47 \\
\hline vdW-DF2 & 2.04 & 5.72 & 5.92 & 2.95 & 1.87 & 3.92 & 5.43 & 0.29 & 3.51 \\
\hline
\end{tabular}

${ }^{a}$ LCD, or largest cavity diameters, is defined as the diameter of largest sphere that can fit in the pore of the MOFs. ${ }^{b}$ PLD, or pore limiting diameters, is defined as the largest sphere is which able to move in a path through the MOFs.

${ }^{c}$ Average mean unsigned percentage error (AMUPE) of all the structural properties.

Supplementary Materials: The following are available online at http://www.mdpi.com/1420-3049/25/7/1552/s1. See Supplementary Materials for tables of $k$ points, oxidation states, and initial magnetic moments of metal centers, magnetic ground states, experimental and calculated lattice constants, unit cell volumes, pore sizes (PLD and LCD), bond lengths, bond angles, and torsional angles of MOFs and their mean signed and unsigned errors. The supplementary materials also includes the temperatures of the X-ray measurements.

Author Contributions: Funding acquisition, D.G.T.; Investigation, I.C. and D.G.T.; Methodology, I.C. and D.G.T.; Writing-original draft, I.C.; Writing-review \& editing, D.G.T. All authors have read and agreed to the published version of the manuscript.

Funding: This research was supported as part of the Nanoporous Materials Genome Center by the U.S. Department of Energy, Office of Basic Energy Sciences, Division of Chemical Sciences, Geosciences, and Biosciences, under award DE-FG02-17ER16362.

Acknowledgments: The authors are grateful to David Sholl and other members of the Nanoporous Materials Genome Center for helpful interactions.

Conflicts of Interest: The authors declare no conflict of interest. 


\section{References}

1. Howarth, A.J.; Peters, A.W.; Vermeulen, N.A.; Wang, C.T.; Hupp, J.T.; Farah, O.K. Best practices for the synthesis, activation, and characterization of metal-organic frameworks. Chem. Mater. 2017, 29, 26-39. [CrossRef]

2. Férey, G. Hybrid porous solids: Past, present, future. Chem. Soc. Rev. 2008, 37, 191-214. [CrossRef] [PubMed]

3. Tranchemontagne, D.J.; Mendoza-Cortes, J.L.; O'Keeffe, M.; Yaghi, O.M. Secondary building units, nets and bonding in the chemistry of metal-organic frameworks. Chem. Soc. Rev. 2009, 38, 1257-1283. [CrossRef] [PubMed]

4. Wang, H.; Zhang, L.; Chen, Z.; Hu, J.; Li, S.; Wang, Z.; Liu, J.; Wang, X. Semiconductor heterojunction photocatalysts: Design, construction, and photocatalytic performances. Chem. Soc. Rev. 2014, 43, 5234-5244. [CrossRef]

5. Shah, M.S.; Tsapatsis, M.; Siepmann, J.I. Hydrogen sulfide capture: From absorption in polar liquids to oxide, zeolite, and metal-organic framework adsorbents and membranes. Chem. Rev. 2017, 117, 9755-9803. [CrossRef]

6. Ravelli, D.; Dondi, D.; Fagnoni, M.; Albini, A. Photocatalysis. A multi-faceted concept for green chemistry. Chem. Soc. Rev. 2009, 38, 1999-2011. [CrossRef]

7. Gust, D.; Moore, T.A.; Moore, A.L. Solar Fuels via Artificial Photosynthesis. Acc. Chem. Res. 2009, 42, 1890-1898. [CrossRef]

8. Zhao, Y.; Song, Z.; Li, X.; Sun, Q.; Cheng, N.; Lawes, S.; Sun, X. Metal-organic frameworks for energy storage and conversion. Energy Storage Mater. 2016, 2, 35-62. [CrossRef]

9. Linsebigler, A.L.; Lu, G.Q.; Yates, J.T. Photocatalysis on $\mathrm{TiO}_{2}$ Surfaces: Principles, Mechanisms, and Selected Results. Chem. Rev. 1995, 95, 735-758. [CrossRef]

10. Yuan, S.; Qin, J.-S.; Lollar, C.T.; Zhou, H.-C. Stable metal-organic frameworks with group 4 metals: Current status and trends. ACS Cent. Sci. 2018, 4, 440-450. [CrossRef]

11. Wu, X.-P.; Choudhuri, I.; Truhlar, D.G. Computational studies of photocatalysis with metal-organic frameworks. Energy Environ. Mater. 2019, 2, 251-263. [CrossRef]

12. Rogge, S.M.J.; Bavykina, A.; Hajek, J.; Garcia, H.; Olivos-Suarez, A.I.; Sepúlveda-Escribano, A.; Vimont, A.; Clet, G.; Bazin, P.; Kapteijn, F.; et al. Metal-organic and covalent organic frameworks as single-site catalysts. Chem. Soc. Rev. 2017, 46, 3134-3184. [CrossRef] [PubMed]

13. Bernales, V.; Ortuño, M.A.; Truhlar, D.G.; Cramer, C.J.; Gagliardi, L. Computational design of functionalized metal-organic framework nodes for catalysis. ACS Cent. Sci. 2018, 4, 5-19. [CrossRef] [PubMed]

14. Xu, W.; Thapa, K.B.; Ju, Q.; Fang, Z.; Huang, W. Heterogeneous catalysts based on mesoporous metal-organic frameworks. Coord. Chem. Rev. 2018, 373, 199-232. [CrossRef]

15. Kohn, W. Nobel Lecture: Electronic structure of matter-wave functions and density functionals. Rev. Mod. Phys. 1999, 71, 1253-1266. [CrossRef]

16. de P. R. Moreira, I.; Illas, F.; Martin, R.L. Effect of Fock exchange on the electronic structure and magnetic coupling in NiO. Phys. Rev. B 2002, 65, 155102. [CrossRef]

17. Partoens, B.; Peeters, F.M. From graphene to graphite: Electronic structure around the K point. Phys. Rev. B 2006, 74, 075404. [CrossRef]

18. Mo, Y.; Tang, H.; Bansil, A.; Taom, J. Accurate lattice geometrical parameters and bulk moduli from a semilocal density functional. AIP Adv. 1991, 8, 095209. [CrossRef]

19. Allen, A.J.; Wong-Ng, W.; Cockayne, E.; Culp, J.T.; Matranga, C. Structural basis of $\mathrm{CO}_{2}$ adsorption in a flexible metal-organic framework material. Nanomaterials 2019, 9, 354. [CrossRef]

20. Nazarian, D.; Ganesh, P.; Sholl, D.S. Benchmarking density functional theory predictions of framework structures and properties in a chemically diverse test set of metal-organic frameworks. J. Mater. Chem. A 2015, 3, 22432-22440. [CrossRef]

21. Perdew, J.P.; Burke, K.; Ernzerhof, M. Generalized gradient approximation made simple. Phys. Rev. Lett. 1996, 77, 3865-3868. [CrossRef] [PubMed]

22. Lianhua, H.; Liu, F.; Hautier, G.; Oliveira, M.J.T.; Marques, M.A.L.; Vila, F.D.; Rehr, J.J.; Rignanese, G.-M.; Zhou, A. Accuracy of generalized gradient approximation functionals for density-functional perturbation theory calculations. Phys. Rev. B 2014, 89, 064305. 
23. Perdew, J.P.; Ruzsinszky, A.; Csonka, G.I.; Vydrov, O.A.; Scuseria, G.E.; Constantin, L.A.; Zhou, X.; Burke, K. Restoring the Density-Gradient Expansion for Exchange in Solids and Surfaces. Phys. Rev. Lett. 2008, 100, 136406. [CrossRef] [PubMed]

24. Zhao, Y.; Truhlar, D.G. Construction of a generalized gradient approximation by restoring the density-gradient expansion and enforcing a tight Lieb-Oxford bound. J. Chem. Phys. 2008, 128, 184109. [CrossRef] [PubMed]

25. Yu, H.S.; He, X.; Truhlar, D.G. MN15-L: A new local exchange-correlation functional for Kohn-Sham density functional theory with broad accuracy for atoms, molecules, and solids. J. Chem. Theory Comput. 2016, 12, 1280-1293. [CrossRef] [PubMed]

26. Wang, Y.; Jin, X.; Yu, H.S.; Truhlar, D.G.; He, X. Revised M06-L functional for improved accuracy on chemical reaction barrier heights, noncovalent interactions, and solid-state physics. Proc. Natl. Acad. Sci. USA 2017, 114, 8487-8492. [CrossRef]

27. Sun, J.; Ruzsinszky, A.; Perdew, J.P. Strongly constrained and appropriately normed semilocal density functional. Phys. Rev. Lett. 2015, 115, 036402. [CrossRef]

28. Perdew, J.P.; Ruzsinszky, A.; Csonka, G.I.; Constantin, L.A.; Sun, J. Workhorse Semilocal density functional for condensed matter physics and quantum chemistry. Phys. Rev. Lett. 2009, 103, 026403. [CrossRef]

29. Grimme, S. Semiempirical GGA-type density functional constructed with a long-range dispersion correction. J. Comp. Chem. 2006, 27, 1787-1799. [CrossRef]

30. Grimme, S.; Antony, J.; Ehrlich, S.; Krieg, H. A consistent and accurate ab initio parametrization of density functional dispersion correction (DFT-D) for the 94 elements H-Pu. J. Chem. Phys. 2010, 132, 154104. [CrossRef]

31. Lee, K.; Murray, E.D.; Kong, L.; Lundqvist, B.I.; Langreth, D.C. Higher-accuracy van der Waals density functional. Phys. Rev. B 2010, 82, 081101. [CrossRef]

32. Román-Pérez, G.; Soler, J.M. Efficient implementation of a van der waals density functional: Application to double-wall carbon nanotubes. Phys. Rev. Lett. 2009, 103, 096102. [CrossRef] [PubMed]

33. Frenzer, W.; Wartchow, R.; Bode, H. Crystal structure of disilver 2,5-dichloro-[1,4]benzoquinone-3,6-diolate, $\mathrm{Ag}_{2}\left(\mathrm{C}_{6} \mathrm{O}_{4} \mathrm{Cl}_{2}\right)$. Zeitschrift Fur Kristallographie 1997, 212, 237. [CrossRef]

34. Tian, Y.-Q.; Yao, S.-Y.; Gu, D.; Cui, K.-H.; Guo, D.-W.; Zhang, G.; Chen, Z.X.; Zhao, D.-Y. Cadmium imidazolate frameworks with polymorphism, high thermal stability, and a large surface area. Chem. Eur. J. 2010, 16, 1137-1141. [CrossRef] [PubMed]

35. Wang, C.C.; Kuo, C.T.; Yang, J.C.; Lee, G.H.; Shih, W.J.; Sheu, H.S. Assemblies of two new metal-organic frameworks constructed from $\mathrm{Cd}(\mathrm{II})$ with 2,2'-bipyrimidine and cyclic oxocarbon dianions $\mathrm{C}_{\mathrm{n}} \mathrm{O}_{\mathrm{n}}{ }^{2-}(\mathrm{n}=4,5)$. Cryst. Growth Des. 2007, 7, 1476-1482. [CrossRef]

36. Bowden, T.A.; Milton, H.L.; Slawin, A.M.Z.; Lightfoot, P. Hydrothermal syntheses and crystal structures of three zinc succinates: $\mathrm{Zn}\left(\mathrm{C}_{4} \mathrm{H}_{4} \mathrm{O}_{4}\right)-\alpha, \mathrm{Zn}\left(\mathrm{C}_{4} \mathrm{H}_{4} \mathrm{O}_{4}\right)-\beta$ and $\mathrm{K}_{2} \mathrm{Zn}\left(\mathrm{C}_{4} \mathrm{H}_{4} \mathrm{O}_{4}\right)_{2}$. Dalton Trans. 2003, 936-939. [CrossRef]

37. Xie, L.H.; Lin, J.B.; Liu, X.M.; Wang, Y.; Zhang, W.X.; Zhang, J.P.; Chen, X.M. Porous coordination polymer with flexibility imparted by coordinatively changeable lithium ions on the pore surface. Inorg. Chem. 2010, 49, 1158-1165. [CrossRef]

38. Kurmoo, M.; Kepert, C.J. Hard magnets based on transition metal complexes with the dicyanamide anion, $\left\{\mathrm{N}(\mathrm{CN})_{2}\right\}^{-}$. New J. Chem. 1998, 22, 1515-1524. [CrossRef]

39. Cao, R.; Shi, Q.; Sun, D.F.; Hong, M.C.; Bi, W.H.; Zhao, Y.J. Syntheses and characterizations of Copper(II) polymeric complexes constructed from 1,2,4,5-benzenetetracarboxylic acid. Inorg. Chem. 2002, 41, 6161-6168. [CrossRef]

40. Ouellette, W.; Prosvirin, A.V.; Chieffo, V.; Dunbar, K.R.; Hudson, B.; Zubieta, J. Solid-state Coordination Chemistry of the $\mathrm{Cu}$ /triazolate/X System $\left(\mathrm{X}=\mathrm{F}-, \mathrm{Cl}-, \mathrm{Br}-, \mathrm{I}-, \mathrm{OH}-\right.$, and $\left.\mathrm{SO}_{4}\left({ }^{2-}\right)\right)$. Inorg. Chem. 2006, 45, 9346-9366. [CrossRef]

41. Kong, X.J.; Zhuang, G.L.; Ren, Y.P.; Long, L.S.; Huang, R.B.; Zheng, L.S. In situ cyclodehydration of iminodiacetic acid into 2,5-diketopiperazine-1,4-diacetate in lanthanide-based coordination polymers. Dalton Trans. 2009, 1707-1709. [CrossRef] [PubMed]

42. Molinier, M.; Price, D.J.; Wood, P.T.; Powell, A.K. Biomimetic control of iron oxide and hydroxide phases in the iron oxalate system. J. Chem. Soc. Dalton Trans. 1997, 4061-4068. [CrossRef]

43. Hou, J.J.; Zhang, X.M. Structures and magnetic properties of a series of metal phosphonoacetates synthesized from in situ hydrolysis of triethyl phosphonoacetate. Cryst. Growth Des. 2006, 6, 1445-1452. [CrossRef] 
44. Zhang, X.J.; Xing, Y.H.; Han, J.; Zeng, X.Q.; Ge, M.F.; Niu, S.Y. A series of novel ln-succinate-oxalate coordination polymers: Synthesis, structure, thermal stability, and fluorescent properties. Cryst. Growth Des. 2008, 8, 3680-3688. [CrossRef]

45. Cavka, J.H.; Jakobsen, S.; Olsbye, U.; Guillou, N.; Lamberti, C.; Bordiga, S.; Lillerud, K.P. A New zirconium inorganic building brick forming metal organic frameworks with exceptional stability. J. Am. Chem. Soc. 2008, 130, 13850-13851. [CrossRef]

46. Li, H.; Eddaoudi, M.; O’Keeffe, M.; Yaghi, O.M. Design and synthesis of an exceptionally stable and highly porous metal-organic framework. Nature 1999, 402, 276-279. [CrossRef]

47. Chung, Y.G.; Camp, J.; Haranczyk, M.; Sikora, B.J.; Bury, W.; Krungleviciute, V.; Yildirim, T.; Farha, O.K.; Sholl, D.S.; Snurr, R.Q. Computation-ready, experimental metal-organic frameworks: A tool to enable high-throughput screening of nanoporous crystals. Chem. Mater. 2014, 26, 6185-6192. [CrossRef]

48. Tran, F.; Kalantari, L.; Traoré, B.; Rocquefelte, X.; Blaha, P. Nonlocal van der Waals functionals for solids: Choosing an appropriate one. Phys. Rev. Mater. 2019, 3, 063602. [CrossRef]

49. Tran, F.; Stelzl, J.; Blaha, P. Rungs 1 to 4 of DFT Jacob's ladder: Extensive test on the lattice constant, bulk modulus, and cohesive energy of solids. J. Chem. Phys. 2016, 144, 204120. [CrossRef]

50. Kresse, G.; Hafner, J. Ab initio molecular-dynamics simulation of the liquid-metal-amorphous-semiconductor transition in germanium. Phys. Rev. B 1994, 49, 14251-14259. [CrossRef]

51. Kresse, G.; Furthmüller, J. Efficiency of ab-initio total energy calculations for metals and semiconductors using a plane-wave basis set. J. Comput. Mater. Sci. 1996, 6, 15-50. [CrossRef]

52. Blöchl, P.E. Projector augmented-wave method. Phys. Rev. B Condens. Matter Mater. Phys. 1994, 50, 17953-17979. [CrossRef] [PubMed]

53. Monkhorst, H.J.; Pack, J.D. Special points for Brillouin-zone integrations. Phys. Rev. B 1976, 13, 5188-5192. [CrossRef]

54. Martin, R.L.; Smit, B.; Haranczyk, M. Addressing challenges of identifying geometrically diverse sets of crystalline porous materials. J. Chem. Inf. Model. 2012, 52, 308-318. [CrossRef]

55. Willems, T.F.; Rycro, C.; Kazi, M.; Meza, J.C.; Haranczyk, M. Algorithms and tools for high-throughput geometry- based analysis of crystalline porous materials. Microporous Mesoporous Mater. 2012, 149, 134-141. [CrossRef]

56. Pinheiro, M.; Martin, R.L.; Rycro, C.H.; Jones, A.; Iglesia, E.; Haranczyk, M. Characterization and comparison of pore landscapes in crystalline porous materials. J. Mol. Graphics Modell. 2013, 44, 208-219. [CrossRef]

57. Zeo++ Software. Available online: http://www.Zeoplusplus.org/about.html (accessed on 24 January 2020).

58. Jones, P.G. Crystal structure determination: A critical view. Chem. Soc. Rev. 1984, 13, 157-172. [CrossRef]

59. Haldoupis, E.; Nair, S.; Sholl, D.S. Efficient calculation of diffusion limitations in metal-organic framework materials: A tool for identifying materials for kinetic separations. J. Am. Chem. Soc. 2010, 132, 7528-7539. [CrossRef]

60. Krukau, A.V.; Vydrov, O.A.; Izmaylov, A.F.; Scuseria, G.E. Influence of the exchange screening parameter on the performance of screened hybrid functionals. J. Chem. Phys. 2006, 125, 224106. [CrossRef]

61. Verma, P.; Truhlar, D.G. HLE17: An improved local exchange-correlation functional for computing semiconductor band gaps and molecular excitation energies. J. Phys. Chem. C 2017, 121, 7144-7154. [CrossRef]

62. Choudhuri, I.; Truhlar, D.G. HLE17: An efficient way to predict band gaps of complex materials. J. Phys. Chem. C 2019, 123, 17416-17424. [CrossRef]

(C) 2020 by the authors. Licensee MDPI, Basel, Switzerland. This article is an open access article distributed under the terms and conditions of the Creative Commons Attribution (CC BY) license (http://creativecommons.org/licenses/by/4.0/). 